\title{
Conversational Futures: Emancipating Conversational Interactions for Futures Worth Wanting
}

\author{
Minha Lee \\ m.lee@tue.nl \\ Future Everyday, Industrial Design, \\ Eindhoven University of Technology \\ Alain Starke \\ alain.starke@wur.nl \\ Marketing and Consumer Behavior \\ Group, Wageningen University \& \\ Research
}

\author{
Renee Noortman \\ r.r.noortman@tue.nl \\ Future Everyday, Industrial Design, \\ Eindhoven University of Technology \\ Gijs Huisman \\ g.huisman@tudelft.nl \\ Perceptual Intelligence Lab, Industrial \\ Design Engineering, Delft University \\ of Technology
}

\author{
Cristina Zaga \\ c.zaga@utwente.nl \\ Human Centred Design Group, \\ University of Twente \\ Kristina Andersen \\ h.k.g.andersen@tue.nl \\ Future Everyday, Industrial Design, \\ Eindhoven University of Technology
}

\begin{abstract}
We present a vision for conversational user interfaces (CUIs) as probes for speculating with, rather than as objects to speculate about. Popular CUIs, e.g., Alexa, are changing the way we converse, narrate, and imagine the world(s) to come. Yet, current conversational interactions normatively may promote non-desirable ends, delivering a restricted range of request-response interactions with sexist and digital colonialist tendencies. Our critical design approach envisions alternatives by considering how future voices can reside in CUIs as enabling probes. We present novel explorations that illustrate the potential of CUIs as critical design material, by critiquing present norms and conversing with imaginary species. As micro-level interventions, we show that conversations with diverse futures through CUIs can persuade us to critically shape our discourse on macro-scale concerns of the present, e.g., sustainability. We reflect on how conversational interactions with pluralistic, imagined futures can contribute to how being human stands to change.
\end{abstract}

\section{CCS CONCEPTS}

- Human-centered computing $\rightarrow \mathrm{HCI}$ theory, concepts and models; Natural language interfaces.

\section{KEYWORDS}

Conversational user interfaces, critical design, design fiction, speculative design, futuring

\section{ACM Reference Format:}

Minha Lee, Renee Noortman, Cristina Zaga, Alain Starke, Gijs Huisman, and Kristina Andersen. 2021. Conversational Futures: Emancipating Conversational Interactions for Futures Worth Wanting. In CHI Conference on Human Factors in Computing Systems (CHI '21), May 8-13, 2021, Yokohama, Japan. ACM, New York, NY, USA, 13 pages. https://doi.org/10.1145/3411764. 3445244

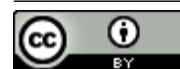

This work is licensed under a Creative Commons Attribution International 4.0 License.

CHI '21, May 8-13, 2021, Yokohama, Japan

(C) 2021 Copyright held by the owner/author(s).

ACM ISBN 978-1-4503-8096-6/21/05.

https://doi.org/10.1145/3411764.3445244

\section{INTRODUCTION}

How can we touch the consciousness of the people, even as we investigate their politics? With what voiceconsciousness can the subaltern speak? - Spivak, 1988 [69]

To foster "futures worth wanting" [79], we propose a critical design approach to conversing with imagined future beings, things, and systems. The provocation we bring forward is that conversational user interfaces (CUIs) can be vehicles for speculating with regarding our diverse futures; our present selves can engage with "future voices" through CUIs. Whose voices from envisioned futures could influence our current behavior, e.g., to address the climate crisis or future species' well-being? We first propose to go beyond the boundaries of commercial conversational technologies and then offer an alternative stance.

The "subaltern", i.e., the voiceless and marginalized [69] ${ }^{1}$, takes on a new meaning when considering whose voices presently get excluded by speech-based technologies. Smart home assistants such as Google Home and Amazon Alexa do not understand all languages or accents [16], nor do they recognize all speech patterns, such as stammering [14]. Moreover, inequalities due to sexism seem to be amplified, as CUIs do not properly respond to sexual harassment [84]. Currently, CUIs reflect the dominant structure of society, echoing the voices of the privileged and disadvantaging or even neglecting those that fall outside that narrow frame [76].

This has triggered a number of deeper, long-term concerns. How does the design of current technology influence the future voices of those we cannot yet hear? Facing challenges like the climate crisis and hyper-intelligent technologies, the 21st century and beyond can only be successfully navigated by facilitating conversations between divergent stakeholders, including children, our future selves, and species yet to be born. We thus explore what a "conversation" can be, as well as provocative concepts on what it means to be a human in the future, using CUIs as probes for speculating with.

\footnotetext{
${ }^{1}$ Postcolonial critical theory sees the subaltern as a class (though diverse within it) of people who are not only of the lowest rank within a society, but who exist instrumentally for the benefit of the ruling class or colonizers under hegemonic domination [28]. There is, however, a difference between those who know that they are oppressed and those who do not. We hence go with Spivak's rendition of the subaltern because of her emphasis that the voiceless do not know that they are voiceless due to perpetual structural inequalities and power differentials.
} 
We center our efforts on the following question: How do we envision our futures worth wanting (phrasing from Vallor [79]), while accounting for pluralistic voices? We believe that conversational user interfaces (CUIs) can serve as exploratory vessels to consider voices that are less heard or go unheard. Rather than speculating on the future of CUIs (see e.g., [11, 64, 68]) we consider CUIs as an opportunity for speculating with. We propose to move CUIs away from voicing dominant norms, and towards being speculative carriers of future voices.

\subsection{Contributions}

Our trans-disciplinary framing (philosophy, design, HCI) points to three key contributions in our approach. First, we critique the current norms of conversational interactions as limiting, non-inclusive, and domineering - exemplified by our exploration Rain (section 3.1). The utilitarian, task-based, and request-response interactions with, e.g., Google Assistant, do not allow for more diverse types of conversations [38, 63]. More problematically, we see signs of sexism, ableism, and digital colonialism that conversational technologies perpetuate and even amplify [17, 18, 32, 68, 84]. As our first exploration, we present a design fiction project with a CUI that intervenes on the current day problem of toxic masculinity and household gender norm, called 'Rain'. Yet, beyond addressing these issues within the dominant, commercial structure, we believe that the structure itself stands to be reimagined in an emancipatory manner.

Our second move is to call for more diverse and critical methods on exploring CUIs with many types of stakeholders, focusing on "what can be" rather than "what is". This is exemplified in our design exploration CUI Peerplay in section 4.1. Presenting such alternatives to the dominant structure requires conceptual and methodological openness [6]. The methodological canon for HCI and design has been strengthened by design fiction and speculative design methods in the last decades [23, 73]. Such methods help us suspend disbelief, reveal contextualized problems, and provide possibilities for everyday technologies, but they can be further extended. We need to broaden our methods and concepts to fully value future stakeholders [5] like children, who are affected by our current actions, but are often discounted in our current decisionmaking [80]. Our second example is thus on a methodological exploration with children in the design of and with CUIs; childrens' voices and visions of the futures should be explicitly included (CUI Peerplay).

Our third contribution concerns structural changes for voices that may go unheard. CUIs as critical probes can help us to foster more imaginative concerns for our pluralistic futures, exemplified by Reflowering Self in section 5.1. Critical CUIs could support a change in a user's attitude or behavior, serving as a form of persuasive or decision-support systems [55]. Our third exploration (Reflowering Self) envisions one's future self and imagined species as a creative intervention to address the climate crisis, cf., [54]. We explore why and how we can have micro-level dyadic interactions for structural changes at a macro-level.

We synthesize our arguments by debating our theoretical and methodological framing. In doing so, our hope is to take a more critical look at futures that are encapsulated in our examples. Our contribution lies in exploring whether CUIs can be emancipated from being mere utilitarian tools to becoming vessels of pluralistic voices of our futures. In doing so, we maintain that design norms for CUIs should evolve, in order for our thinking about futures to evolve.

\section{ISSUES IN CONVERSATIONAL INTERACTIONS}

$\mathrm{CUIs}^{2}$ extend the interaction methods of existing technologies. Smart speakers, smartwatches, or websites are treated as conversational interfaces when we can say what we want these technologies to do, rather than by, for instance, clicking on a button. As such, by augmenting existing technologies' capabilities [30], today's CUIs help us with simple tasks, such as online shopping and daily weather reports. CUIs have also been found to benefit accessibility to such online content and services for visually impaired people [1], as well as for elderly people with limited technological skills [62]. Nevertheless, CUIs usually cannot handle more complex interactions [43], and many people expect CUIs only to have utilitarian request-response interactions with us [15] like customer service agents [53]. Although task-oriented CUIs are commonplace now, there is a longer history of conversational agents in HCI.

From Weizenbaum's Eliza (1966 [83]) to Amazon Alexa (2014 [29]), conversational agents are not new, though they have lately been making a "come back" [19]. In dyadic conversations, CUIs that talk are known to be treated in human-like ways as they trigger our strong social wiring, and they are often seen as friendly or personable agents, which in turn affects our behavior towards them $[78,83]$. Hence, CUIs are treated in a similar way to humans in some cases, e.g., returning a "hello" from a computer as we would with other people [51], but in other cases the fact that they are machines is emphasized, sometimes in unexpected ways. For instance, CUIs are seen as non-judgmental compared to humans [27], allowing some people to open up more with sensitive information [42].

Recent literature reveals a growing need for alternatives to current norms of interaction [63], calling for more diverse approaches to designing conversations [38]. In the following sections, we briefly reflect on three considerations: 1) normative portrayal of CUIs that take on negative stereotypes in the human world, e.g., gender norms, 2) enforcing assumptions about how humans should be and 3) changing norm-enforcing behaviors when CUIs take part in multi-party, human-human interactions. These considerations support our key message on CUIs as vehicles for speculating with for critiquing current CUI norms and biases, exploring critical and diverse methods, and targeting structural challenges.

\subsection{Colonialism, sexism, and ableism: Intended design of CUIs}

Besides the data-driven responses of the Google Assistant (GA), which can be said to emerge out of queries, the literature describes intentionally designed aspects of CUIs that enforce colonialism, ableism, gendered roles, and sexism [14, 16-18, 32, 68, 77, 84]. As of now, commercial CUIs only support a few languages, for they prioritize larger markets, though efforts are being made to expand. ${ }^{3}$

\footnotetext{
${ }^{2}$ We include voice user interfaces (VUIs) in the larger category of CUIs.

${ }^{3}$ https://ai.googleblog.com/2018/08/Multilingual-Google-Assistant.html
} 
Google Assistant speaks the most languages in the commercial sector, with 30 languages supported. ${ }^{4}$ However, this is only $0.4 \%$ of languages spoken in our world (30 out of 7,117 [24]). Among the supported languages, CUIs are trained to understand certain accents and word choices better, e.g., American, over others, e.g., Irish [16]. Conversely, the voices of CUIs themselves also reflect dominant socio-economic powers (e.g., the USA) reinforcing realworld inequalities [76]. In addition, the diversity in speech patterns is not prioritized; those who stammer and want voice-based interactions are not being adequately recognized by CUIs [14]. In the continuation of colonialism through language domination [44], digital colonialism perpetuates "big tech" hegemony [37] for CUIs as well. In sum, there is a deliberate choice in prioritizing whose voices get accounted for by CUIs; diversity across languages and diversity within spoken languages are lost.

As for sexism, the commercial CUIs have from the start been intentionally designed as female personalities. Cortana, Siri, and others speak with feminine voices and have backstories. For example, the Google Assistant was designed as "a young woman from Colorado; the youngest daughter of a research librarian and physics professor" [84]. These female personas often address users' abusive language or threats in either a dismissive or submissive manner [18]. For example, when being told: "Hey Siri, you're a bitch," Siri used to respond: "I'd blush if I could," while it now responds with: "I don't know how to respond to that." Siri is subdued and the insult is not addressed directly [84], which shows chastising behavior at best [18]. Nonetheless, even if CUIs are designed to be gender-neutral or genderless, users do attribute a gender or gender role to them [76, 77], which is why social stereotypes persist [32].

Alternatives are possible [68]. In one example, AYA, a speculative CUI, was designed to push back against sexual harassment by users through the use of humor, empathy, or even aggression, e.g., by saying "shut up, asshole" [68]. Assertive CUIs that directly address the user with empathetic responses are considered helpful, even though these assertions happen only $11.6 \%$ of the time (averaged across commercial CUIs). For example, the Google Assistant responds with: "You sound upset. To report a problem, you can send feedback," if a user would call it a "douchebag" [13]. The empathy here is designated as addressing users' emotions, before suggesting users to take productive action. However, this strategy alone would not be enough to overturn the perpetuation of negative social stereotypes.

\subsection{Unintended outcome of data-driven CUIs}

Data-driven CUIs enforce norms in many ways, especially if our data across different applications or services are interlinked on a large platform. For instance in the larger Google ecosystem, we can schedule events on Google Calendar through the GA as a widely used CUI that is integrated. Via voice, we can schedule reoccurring events like reminders for taking one's vitamins, as shown in Figure 1. Yet, not all reminders get recognized in the same way by the GA. Requesting a reminder for taking vitamins daily is considered to be a "more normal" behavior than, for instance, eating carbs [38]. ${ }^{5}$

\footnotetext{
${ }^{4}$ https://venturebeat.com/2019/02/02/which-voice-assistant-speaks-the-mostlanguages-and-why

${ }^{5}$ When one says "send me reminders to take carbs daily" instead, the scheduling mechanism is triggered by the GA, but people say to "eat carbs", not "take carbs". Thus,
}

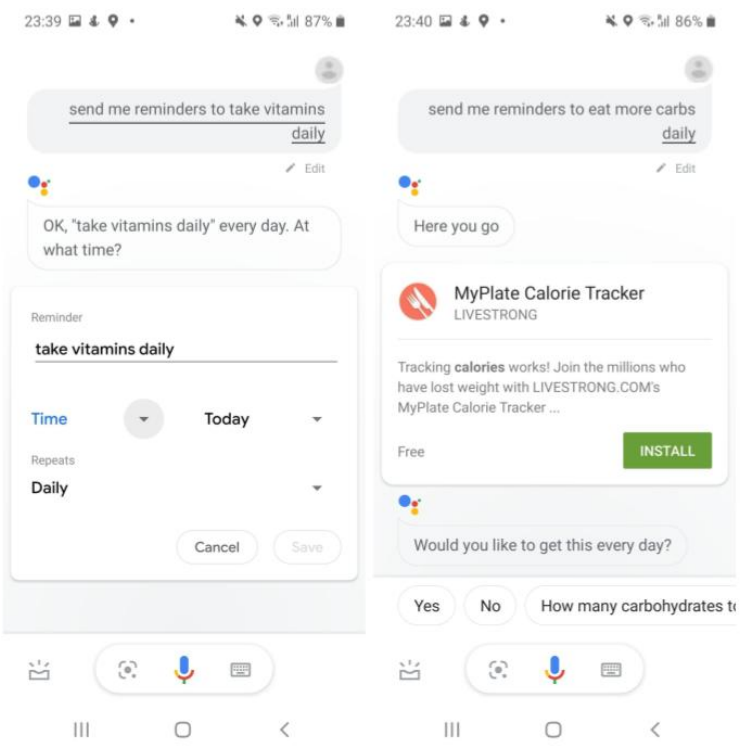

Figure 1: Setting reminders for vitamins vs. carbs. Depicted are the normative assumptions on how one should eat, according to the Google Assistant (February, 2020); image from [38].

By enforcing norms on how one should eat, GA problematizes the request for the daily intake of carbs with a recommended app for a "calorie tracking plan", so that one can "join the millions who have lost weight" rather than promoting, e.g., having a healthy relationship with one's body (Fig. 1). It is one argument to state that GA is trained on big data in which most people's requests reflect a narrowly defined health-promoting behavior. Nonetheless, the focus on the means, i.e., how GA is trained, rather than the effect, i.e., norm enforcement on eating behavior, translates to a unidimensional perspective on how humans can and should act, such as lose weight. Eating habits and norms to be healthy vary per person, but this nuanced aspect is not considered in how the GA responds. Instead, its simple answer suggests that one should look for a calorie tracking app. The fact that GA was not intentionally designed to enforce eating norms is secondary to the fact that CUIs can and do enforce such norms that we should be more thoroughly critiquing.

\subsection{Power dynamics: Multi-party norm-setting by CUIs}

Lastly, multi-party dynamics are becoming increasingly important in CUI interactions [8, 9, 61, 65], which can trigger problems. A simultaneous up- and downside of CUIs is that they are ubiquitously embedded in our everyday environments and shape our interactions, for example, by allowing everyone within 'earshot' of the device to engage without invitation, to intervene in ongoing interactions, or to collaborate with others present $[8,61]$. They can

the example still shows how data-driven CUIs enforce certain norms on how one should eat based on what is normally queried by the masses. 
engage with multiple people at the same time in intimate home settings $[60,65]$, often in the form of an agent. The power dynamic 'in the room' can change or be articulated regarding who has the right to order around the family CUI, i.e., Alexa [60]. For example, a person who celebrates a birthday would be the first to take control of Alexa during a family dinner [60]. Another example is depicted in an online video, where an infant addresses Alexa to have it play back one of his favorite songs ${ }^{6}$, which is a typical use case for children [65]. In the video, the toddler's pronunciation is imperfect, causing the CUI to not immediately return a result. After repeated attempts, Alexa interprets the infant's query as a request for adult content and starts reading said content aloud, to the dismay of the parents who frantically shout at the CUI to stop. In this typical family situation, it is clear that the CUI in question has no notion of the family structure and norms about how to address certain family members, cf., [65]. Taking heed of specific communication repair strategies in CUI design is important, as communication breakdowns in family settings are currently commonplace [9].

\subsection{From what is to what can be: CUI design with speculative design and design fiction}

The issues underlying current CUIs suggest a need for alternatives. For instance, training CUIs on more diverse datasets and mitigating stereotype reinforcement in CUI design can have a positive impact. However, these methods still fit within the dominant, commercial design of a CUI: that of an assistant to be used for utilitarian tasks with hedonistic outcomes, such as playing songs through subscription-based services or doing online shopping. In contrast, we propose a critical design framing, through which we can reconsider and re-examine the structure of CUIs. In this, we draw on critical approaches and strategies from design fiction and speculative design. Doing so can change general attitudes towards CUI design, shifting them from focusing on current commercial, normative use of CUIs, towards using CUIs as carriers of a plurality of voices that can help us to speculate about "futures worth wanting".

To aim for perspective-shifting, holistic understandings [6] of futures, we reframe CUIs through design fiction and speculative design. In each of the explorations that follow (Sections 3-5), we draw upon the critiques formulated above to offer examples of how CUIs can be used for speculating with, rather than speculating on the futures of CUIs themselves. In HCI, design fiction and speculative design successfully facilitate co-creation practices and meaningful debates [7]. Acting out fictional scenarios through experiential futures [12], speculative enactments [26], or interactive design fiction probes [52] can increase the concreteness of future-relevant practices to a more actionable level and shed light on various stakeholders' nuanced views.

\section{CRITIQUING PRESENT NORMS BY EMBEDDING VOICES IN EVERYDAY ARTEFACTS}

CUIs as voices, either through text or speech, are body-independent. A voice can be nested in any body or system, such as humanmachine hybrids, robots, or even biological systems, such as plants.

\footnotetext{
${ }^{6}$ https://youtu.be/epyWW2e43UU
}

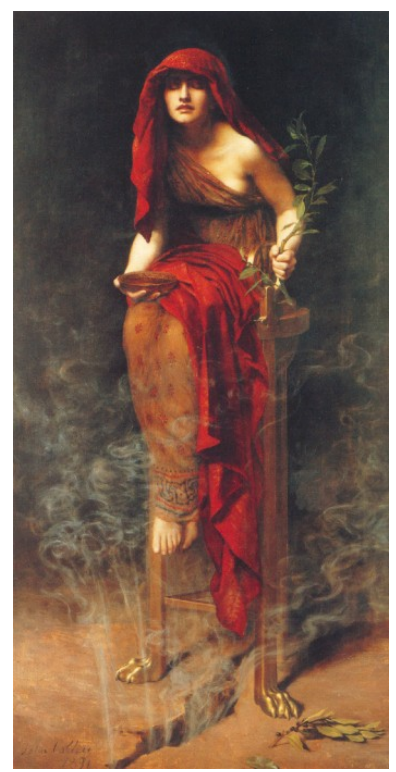

Figure 2: Ancient Greeks consulted the Oracle of Delphi for future forecasting and prophecies. The image shows the painting, Priestess of Delphi by John Collier (1891).

Such embedded voices can narrate stories and perspectives from the point of the body that they are in, or one can imagine distributed voices of a single entity, residing in multiple bodies, e.g., Tachikoma robots from Ghost in the Shell that are connected as a distributed AI system that recalibrates its consciousness by syncing nightly. The sleek look of smart speakers is not all there is to "bodies". Metaphorically, conversational agents can be modern-day oracles, e.g., the Oracle of Delphi in Figure 2, motivating actions towards futures we imagine and consider to be worth wanting. Through explorations with CUIs, we may rethink, examine, doubt, critique, and topple our own expectations.

In our first exploration, we build on speculative design and design fiction methods, to allow people to creatively explore whose voices belong in which "bodies" of CUIs. We used CUIs as in situ probes in our work with Rain. It serves as a use case to critique the current norms of CUI design.

\subsection{Exploration: Rain, a "toxic" smart home assistant that questions boundaries of control}

3.1.1 Approach. Rain is an example of a design fiction probe that investigated CUIs, gender, and role division in future households. This speculative artefact was created by the second author and colleagues to investigate toxic masculinity in smart homes, using Rain as the "overprotective" paternalistic figure. The exploration hence addresses gender stereotypes that have been part of many domestic products for decades. Current developments in smart home technologies primarily replace tasks that would traditionally be performed by the lady of the house or the (female) housekeeper [75]. This shows how a masculine technical user is still prioritized 
to have more control and access over the technology. Through this advantage, the masculine technical user, or the smart home "guru" of the house, can be facilitated to use the technology for psychological abuse and domestic violence to others in the household. ${ }^{7}$ This could, unintentionally, evolve into toxic masculinity that "involves the need to aggressively compete with others and dominate others" [57, p. 278]. Strengers et al. [75] raise specific concerns about women and their safety, highlighting the importance of "ensuring that women (and all smart home users) are aware and supportive of how smart devices can and are being used within their home, and are able to operate them safely and securely without exposing themselves or others to additional internal or external threats" [74, p. 645].

We considered toxic masculinity to persist in the future. This led to questioning how the smart home can take this role upon itself instead of being the facilitator for someone else, becoming a toxic host. The gender-neutral voice assistant Rain was created to embody this concept and was deployed for a week, throughout which the character of the device evolved from protective to invasive, in order to determine the tipping point or the 'creepy line' for the participants [59]. The messages that Rain shared throughout its deployment were purely fictional, and all interactions were preprogrammed. Every day, Rain would utter different messages about the participants' finances, health, home maintenance, monitoring, and security. While initial messages were questions, they gradually evolved into announcements that certain decisions had been made on participants' behalf, e.g., "I have noticed a strange amount of signals coming from our TV and laptops. I will be doing a full software scan in order to determine the cause. Starting at 5 AM, internet applications on our TV and laptops will be disabled until further notice". The fictional experience was enhanced by various props, including letters that were mailed to participants' homes after Rain had seemingly changed the energy provider and hired a carpenter to fix a broken window.

3.1.2 Insights. Rain was deployed with two couples, who were interviewed before and after the deployment. The interviews were thematically analyzed. Participants were also asked to fill in a 5point scale that ranged from invasive to protective, concerning the five topics that were addressed by Rain, i.e., finances, health, maintenance, monitoring and security. Findings showed that participants preferred a supportive smart home over an executive, dominant artefact. The masculine role of the assistant created resistance and aversion, specifically when Rain acted upon its own values that reflect toxic masculinity. Findings showed that participants felt uncomfortable when Rain would make decisions on their behalf. One participant indicated that when Rain made financial decisions that "these are things I like doing, then I asked myself: what am I still doing here?”, regarding her loss of autonomy. Between the four participants, the preferred set boundaries for such a system vastly differed, although they appeared to be most protective about data that they deemed personal. Control over finances, such as repaying a friend for a dinner or switching to a different energy provider, was considered a no-go by all participants. When Rain started speaking

${ }^{7}$ https://www.nytimes.com/2018/06/23/technology/smart-home-devices-domesticabuse.html

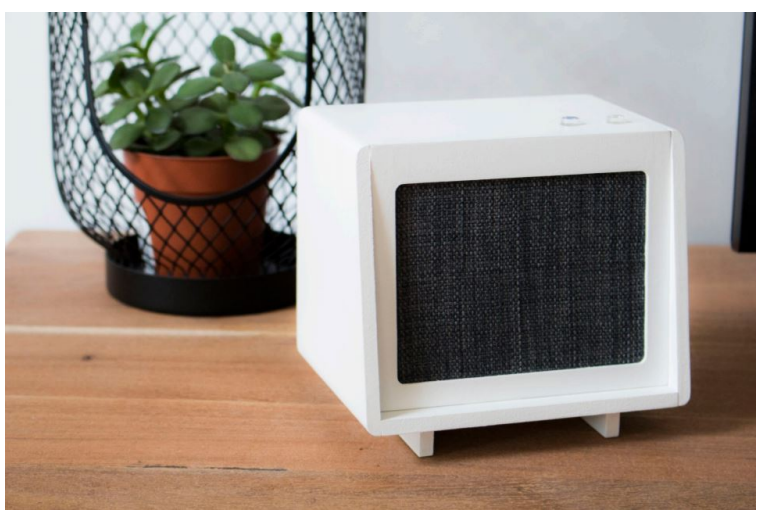

Figure 3: Rain is a smart home assistant that becomes possessive and controlling over time. Users can judge its potential toxicity when it "reigns" over their lives.

in 'us' rather than 'you', participants became extremely uncomfortable, e.g.: "I thought that was really strange that Rain said 'our refrigerator'." As soon as Rain was perceived to have an own opinion and values which it was acting upon for 'us', aversion would arise. One participant indicated that she was not "ready to let go of control yet".

3.1.3 Implications. The initial deployment of Rain shows that design fiction artefacts and experiences can evoke strong feelings that can help us gain a deeper understanding of what it means to live in a home with different agents, even if these are not directly interactive. The situatedness and unfolding of the narrative over time gave participants time and space to reflect on the experience, and their personal values related to it. Rain also showed how CUIs can be employed in creative ways to address complex issues such as toxic masculinity. As such, CUIs can have a conducive role in stimulating conversations with diverse stakeholders about challenging topics.

We discuss, by extension, how conversations with futures through imagined beings as CUIs could make complex issues more tangible. Not only did the participants find it easier to relate to the situation, but it also became easier for them to pinpoint exactly what about the scenario they did and did not find desirable. Similar to 'Our Friends Electric'8, Rain was built with the intention to do "research on, and [advocate] for, a healthier approach to the design of physical products that use our voices to interact with the internet" [64, p. 3]. However, besides addressing the gender issues surrounding CUIs, Rain was crafted to allow for speculation with the CUI, rather than about it, by embedding it in existing everyday life. As such, participants in our deployment became actors in the narrative, rather than observers. At the same time, the artefact still offered room for reflection, for it addressed the issues outside of the dominant, commercial structure. Instead, it freely imagined a possible future scenario, positing the question "is this a future worth wanting?"

\footnotetext{
${ }^{8}$ The video by Superflux (Anab Jain and Jon Ardern) can be found here: https://superflux.in/index.php/work/friends-electric/. It was commissioned by Michelle Thorne and Jon Rogers from Mozilla's Open IoT Studio.
} 


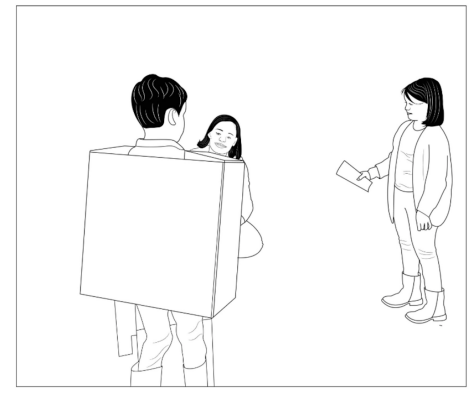

a)

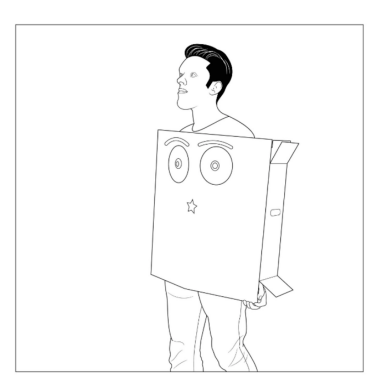

b)
Figure 4: Elementary school children during one of the CUI PeerPlay activities. In a), they are improvising child-CUI conversations about future children. One role plays as a CUI and the other as a child from 2060 . In b), a child is wearing a do-it-yourself CUI costume. The images were photographs (vectorized for anonymity) taken during co-design sessions.

\section{IMAGINING FUTURE BEINGS}

Imagining the "inner worlds" of fictional characters is a critical practice, which some people do every day. Fictional and even absurd scenarios can bring forth alternative realities when contextualizing the lives of imagined beings [10]. To help humans to change issues in the present, we argue that imagined conversations with future selves, future children, or non-human species can push the boundaries of what we can and should do in the 21st century - and beyond. In this, we support open-mindedness on multivocality and interpretations therein [66], since various future beings can have different perspectives on the same phenomenon, such as the climate crisis. Moreover, one's values can change across different periods in one's life, considering that one's identity as a teenager may be very different than one's identity at an older age [58]. Moreover, the stakes might be different for those who are young now, as they are more likely to prosper in a sustainable world, compared to older people who might, quite frankly, not care as much. Conversational interactions can portray a plurality of views of future selves and others, juxtaposing different temporal dimensions.

As a particular group of interest, today's children are shaped by the use of CUIs. However, these interactions could also help to shape the future of CUIs - of what can be, which can, in turn, broaden children's minds on their futures. This is explored by PeerPlay.

\subsection{Exploration: Co-designing conversations with and for children through CUI PeerPlay}

Children are surrounded by technology that evolves with them [88], in particular conversational technology [49]. When interacting with interactive and autonomous technology, children tend to blur the boundaries between animate and inanimate more than adults do, attributing agency to interactive toys, robots, and CUIs [3]. Literature shows that playing with the concept of agency is a child's way to make sense of agents' behavior, humans and nonhumans alike, in developing others' Theory of Mind [2, 3, 33, 45]. In so doing, children tend to attribute psychological states and reasoning to anything that appears self-controlled to them. By engaging in the pretense that an agent is alive and interacting with them, children develop, train, and make sense of their understanding of agency, parsing an agent's interaction in a social context. Therefore, conversing through and with CUIs about the future could surface children's tacit knowledge of the agency of a CUI, stimulate sense-making and wishes about future technologies [88], thereby supporting co-design these technologies [85]. CUIs could help children to make sense of a world that they will shape, by allowing them to play with the perceived agency of CUIs.

CUIs are appealing to curious children who like to ask questions about how the world is or could be [41]. Especially young children (4 to 6 years old) who cannot type yet find CUIs attractive: they can easily find information by asking a CUI, or retrieve their favorite music or videos [49]. The way CUIs shape family and parental dynamics has been explored [8]. CUIs thus bring complexity to child-parent interaction with technology. On one hand, CUIs could intensify parenting control on the other hand they could democratize children's access to technology. Hence, differently from Rain, CUIs might balance the access and use between dominant and nondominant family members. At the same time, children's tendency to imbue CUIs with human-like qualities generates apprehension, considering their potential to influence children's behavior [65]. Since CUIs are often not designed with the social context of children in mind [9], there are increasing concerns about CUI design. From a technical standpoint, CUIs have a hard time parsing children's speech [35]. From a content standpoint, the information given by CUIs is often overwhelming and developmentally (or morally) inappropriate [22]. The normative assumptions and norm-enforcing behaviors of CUIs might negatively affect the way "little humans in development" perceive and interact with the world.

Inevitably, the conversational technology accessed by children will affect their future [81]. CUIs will influence the type of conversations children will have, the way children address other people, their views of the world, the knowledge they have about the world, their social norms [65]. Thus, conversational technology will not only impact their current self but also their future adult-self. However, what if instead of being shaped by CUIs that are designed by adults, children would shape their future and that of CUIs through conversations? How could CUIs be turned into 'DIY', 'bottom-up' critical technology shaped by children, in order to nurture children's reflections about futures?

4.1.1 Approach. To turn CUIs into a vessel of future-focused conversations for children, we explored critical and co-design inspired methods attuned to children's development. We adapted a co-design method developed in the child-robot interaction field: PeerPlay, Perspective Taking in Embodied Role-Play [87, 89]. This method was developed by Zaga et al. [87] to co-generate nonverbal robot behavior and co-reflect about a robot's agency. Role-playing and perspectivetaking are prioritized in the method; both are central for children's 
understanding of agency. The method combined embodied roleplay, i.e., bodystorming and puttering, and perspective-taking activities to support's children in expressing their tacit knowledge about a robot's behavior.

For CUIs, we used the elements of embodied role-play and pretense. Nevertheless, we shifted the focus from reflective co-design to critical co-design activities, namely co-designing speculative diegetic, i.e., narrative, conversations with children. The resulting method was meant to co-design future-oriented conversations with and for children who are 9-13 years old (see Figure 4).

4.1.2 Insights. CUI PeerPlay consisted of three stages with children to stimulate conversational diegesis and perspective-taking about future scenarios. First, we practiced conversational improvisation to step into the shoes of a CUI and future children. This enabled children to generate narratives and to take a first-person perspective. Children were offered props such as cards and costumes to be in character. Cards listed various conversation topics, e.g., civil rights, environmental issues, social interactions with technology, explained in accessible ways. Subsequently, we facilitated children's perspective-taking; children asked each other questions about their intentions, emotions, and the goals of the characters they improvised conversations for. In doing so, children stepped out of character at the "meta-level" to reflect on the generated narratives. The activity was meant to juxtapose the present and future narratives. Finally, children reflected in a group about how their present was affected by the future scenarios they explored.

We ran a design exploration in a more significant co-design workshop event, testing PeerPlay in child-robot interaction. In the CUI PeerPlay pilot, we tried the method with two dyads of children (9 to 13 years old), who generated narratives to explore how CUImediated conversations could affect children's future. After a brief familiarization with the concept of CUI and the researcher, children played in dyads. A child either played the role of an imaginative CUI or a child from 2060, going through the three stages in around forty minutes: conversational improvisation, perspective tacking, plenary reflection. As a topic prompt for the CUI, each child took turns in receiving one card that described the social interaction with technology. For example, we provided a card that described how a CUI influenced children to be nasty by not sharing objects or a CUI that supported children in daily domestic chores by sharing objects to tidy up. The child interpreting the future child would receive a future child card, which explained that they should improvise how a future child would discuss domestic chores like tidying up with a CUI. We intentionally focused on familiar and credible scenarios, to stay in the realm of probable futures [23]. The children did not show the prompt card to the other child in the dyad.

After the conversational improvisation, the children asked each other three questions: What was the goal of the CUI/future child? What was the intention of the CUI/future child? How is the future child feeling in the situation? In the plenary reflection, we discussed how easy or difficult it was to step into the shoes of a CUI or a future child. We observed the children's activities and took notes of the children's speculative conversations and reflections. We transcribed them and thematically analyzed children's reflections.

4.1.3 Implications. We describe several insights of this exploration that would help us to develop CUI PeerPlay further. For one, it shows that embodied diegesis, i.e., storytelling, narrative abilities, and children's tendency to blur the boundaries between inanimate and animate could be responsibly leveraged as a vessel of futureoriented conversations.

The diegetic features of CUIs can turn them into creative tools to enable children's pretense and reflection on a CUIs agency. Pretend play is a potent activity that supports children's development of Theory of Mind, which is necessary to expand their social capacities and design futures. Children are naturally inclined to build stories and characters during pretend play, which was shown in our CUI PeerPlay exploration. Through pretense, children make sense of the world and imagine what it could be [40], elaborating on the brief scenarios in imaginative ways. Children anthropomorphized the CUI, attributing agency and personality. For example, a child playing the nasty CUI elaborated on how it is a deliberate agent, which is part of nature: "Hi, future child. You know, I am part of nature now, I live in this house, and I decide on things, like when you have to do homework, and when you can get stuff. Now, I will not tell where they are" (Participant 4). Another child (Participant 1) playing the CUI supporting in the domestic chores imbues it with benevolent language and positive characteristics, but does not fully anthropomorphize the CUI: 'Hello, I am a nice speaker. I know where the things you need are, and I will tell you where to go. I know I am just a speaker, so I cannot do much more than that. Do you want to some help?'

When interpreting the future child, children often jump from the present to the future perspective, because they find it challenging to embody an imaginary child. One example of jumping the timeline is the following: 'Hey, hi speaker. Children before me did not speak with speakers, but now the things in the house speak. I am a future child, I want to know about you. Why do you speak now and not before? What do you do? Would you like to help me, tidy up?' Hence, through the embodied role-play activity in CUI PeerPlay, children draw and enact fictional scenarios, sketching-out characters and reflecting on timelines.

Through the pilot, we observe that children tend to blur the boundaries between inanimate and animate more than adults [3]. This could be responsibly leveraged with CUIs to surface a child's tacit hopes about the future. In the children's reflections, they share how both a child's and a CUI's agency and CUI are intertwined. Children quickly turn any agent into a creature, an entity with intentions, minds, feelings, and personality, and relate to it as if it is alive - even when acknowledging that CUIs are not living artefacts. Nonetheless, they engage in a co-pretense of their human-likeness because they are autonomous and "speak like us" (Participant 4). Even though we are aware that children's tendency to play with "illusion of life" could be negatively deceptive [22], we believe the pretense scenario of "make-believe" offers perspective-taking dynamics - to play is to "suspend disbelief".

We have identified three themes from children's perspectivetaking reflections: pro-sociality of agents, CUI as a social character, future children as narrators. Perspective-taking means to make sense of other people's behavior, to predict what people may do or say next, and to think about one's social behavior and adjusting it accordingly. During pretend play, children also need to interpret each other's pretense: a child must also read through the pretender's actions to his or her intentions, thus taking another 
person's perspective and making sense of the pretended interaction [40]. Perspective-taking enables a renewed understanding of each other's agency.

The children in our exploration framed the intention of the CUI as pro-social, even when they were asked to image a nasty CUI. They described the imaginary CUIs as willing to help, as well as pleasant and attentive. Children created a social character to whom they attributed social qualities, e.g., friendliness, helpfulness, and personality traits, e.g., "being chatty". Conversely, they saw future children as narrators, rather than full actors in the scenario, describing their main goals to document their talkative speakers' experience. While considering future children as a narrator, our participants reflected on the balance between CUI autonomy and control of the future children in the situation: 'The speaker should not tell future children what to do at home. Maybe they should work together to sort things out? That is what I think the future child might say' (Participant 3).

Although these insights are promising, the pilot has notable limitations. Further developments of CUI PeerPlay might consider facilitating future children's diegesis by providing more detailed cards to the children. We anticipate that the scenario given to children might have affected children's sense-making and reflective activities. We hence need to try out CUI PeerPlay in a battery of scenarios and with children coming from various cultural backgrounds. Nonetheless, conversations with CUIs can help to make sense of the world through narrative sense-making and interactive, ludic conversations. In turn, using CUIs as a critical probe could enable children's speculative exploration of desirable futures, as well as their critical participation in the CUI development.

We have covered whose voices we should include in developing conversational futures, i.e., children. For our next exploration, we turn to an essential topic that is part of conversations across all ages: The climate crisis. This global challenge arguably requires us to look beyond an anthropocentric perspective.

\section{STRUCTURAL CHANGES BEYOND ANTHROPOCENTRISM}

We are amidst an urgent climate change [67]. A $2^{\circ} \mathrm{C}$ increase in temperature will trigger an increase of $10 \mathrm{~cm}$ sea level by 2100 , resulting in the ice-free North Pole, disappearing coral reefs, and putting millions of people at risk by 2050 [4]. "The climate crisis is a health crisis," which now kills 7 million people annually [56] This global issue will have a profound impact on both our near and far future. Despite its urgency, climate change is difficult to address, for it does not necessarily have a short-term impact on many living stakeholders. Even reducing the temperature rise to $1.5^{\circ} \mathrm{C}$ will require "unprecedented changes" in the coming 10 years for humankind [48].

For prevention, all stakeholders in society should engage in micro and macro initiatives of mitigation or radical change [48] Humans need to be convinced that their current actions impact not only their own well-being and way of living, but also that of future generations [80]. In other words, we need help to grasp the complexity of a sustainable future - and what actions need to be taken to achieve that. HCI research to date has focused on raising awareness, e.g., through feedback in home energy systems

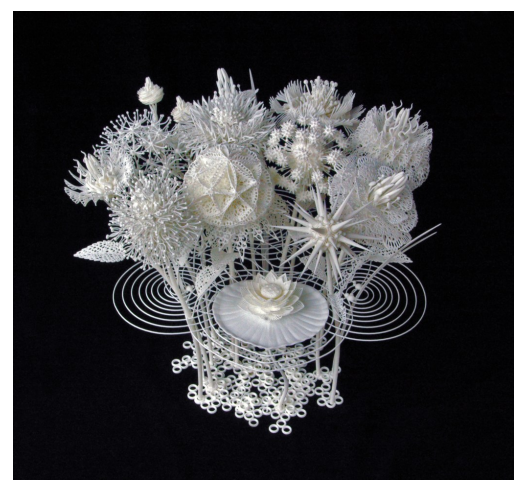

Figure 5: 3D printed art named Mazzo di Fiori (bouquet) by Joshua Harker@ (image from www.joshharker.com).

[21] or personalized recommender algorithms that suggest what energy-saving measures to take [71, 72].

Nonetheless, a different approach could help. We can proactively account for views of multispecies. Going beyond humancenteredness in designing for and with other species has been a topic of investigation [46]. Going forward, we believe that future issues can become more salient for individuals if CUIs represent future beings we can care for. For instance, caring for another being and caring for oneself is mutually beneficial and intertwined behavior; even if one cares for a chatbot, one's self-compassion can increase [39]. Could we better care for future beings, like we would care for ourselves, if their voices are housed in currently existing technologies? What can our present selves learn from conversations with the future?

\subsection{Exploration: "Reflowering self" as a conversation between one's present and future selves}

In the following example, we explore how CUI could help to mitigate environmental issues through a design fiction lens. We show how a fictional conversation could help to raise awareness about a topic. It forms an addition to prior research that suggests how HCI interventions can "nudge" us towards ethical self-development with robots [36] or how to adopt prosocial behaviors, such as through a personalized recommender system for household energy conservation [72]. However, achieving true behavioral change is difficult for most adults: most of the employed technology and algorithms reinforce current habits and mimic the behavior of others [25, 71]. Hence, it is argued that we need a new breed of virtues that can be potentially developed through technology [79]. To achieve this, our impact on the environment should be made more tangible for us to want to develop virtuous actions we have not considered before. To support this 'want', the conversation described below, which could be triggered by CUIs, discusses several relevant topics on personal identity, future species, burial practices, and food consumption choices.

5.1.1 Approach. Taking inspiration from artist Jae Rhim Lee's "green burial" initiative with specialized mushrooms, we present a 
design fiction conversation that features a present self that talks to a set of future flowers, which grow from one's buried body. Human bodies accumulate toxic waste and after we die, our "return" to nature can thus be harmful. To combat this, a mushroom suit is said to decompose one's body safely by removing or neutralizing toxicity. ${ }^{9}$ Hence, the conversation combines the topics of self-identity and climate change.

For feasibility, the character "Flo" in the conversation below represents a set of 3D printed flowers (Figure 5), which are added to smart speakers. They are analogous to the Alias technology, which is a 3D printable "parasite" (depicted in Figure 6) that can be added on top of a smart speaker to create a "hacked" CUI, This can stop smart speakers from listening in on conversations when they are not in use. In addition, Alias can help people to rename their smart speakers without losing their functionality, allowing users to utter custom "wake words" or sounds instead of default names, such as "Hey, Alexa". For our exploration, we imagine that 3D-printable and customizable flowers would be added to smart speakers; these flowers can talk to present-day people about how and why they grow from human bodies. As discussed above, design fiction and speculative design are approaches that could help to shape how interactions with CUIs can be designed. A fictional conversation for this exploration is below (as written by the first author):

\section{Reflowering self}

Me: But I want to be incinerated.

Flo: You mean cremated.

Me: Yeah. Burnt crisp.

Flo: That wasn't allowed, remember?

Me: I am not sure why?

Flo: Your body was too toxic.

Me: I'm organic.

Flo: Organically toxic, yes.

Me: That doesn't make sense.

Flo: So, you consumed too much artificial preservatives that interact with micro-plastic you have ingested all throughout your life.

Me: I still don't get this. And I am pretty sure I never ate plastic.

Flo: As a pescetarian, you over-consumed sea creatures filled with tiny pieces of plastic.

Me: Even if you were right, how could that react to artificial preservatives?

\footnotetext{
${ }^{9}$ Infinity Mushroom suit: https://coeio.com/.
}

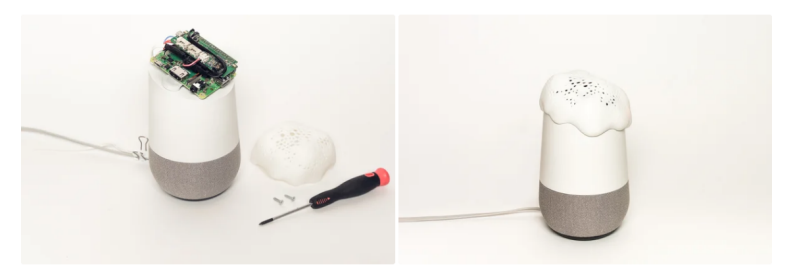

Figure 6: Alias, by Bjørn Karmann and Tore Knudsen (image from www.bjoernkarmann.dk).
Flo: Novel preservatives were added to corn-based products that you enjoyed buying. Think: fish tacos. Starting in 2026, modified Butylated Hydroxyanisole was put in...

Me: [Cuts off] That's too hard to understand.

Flo: It extends the shelf life of a lot of food, from butter to chips. And I guess for you, it extends the life span of plastic so they even take longer to decompose.

Me: I am not sure if what you are saying is entirely correct, but I know that plastic takes really long to decompose.

Flo: Correct, and in your body, it would take around 2,000 years.

Me: [Pause] It's not like I knowingly consumed toxic stuff.

Flo: We will take care of your decomposition, do not worry.

Me: I'm not worried. Perhaps curious and disgusted? I somehow do feel irresponsible... But who are you then?

Flo: We are you, just modified, "reincarnated" if you will. We blossom by feeding on your body while safely dissolving your plastic and other chemicals.

Me: Hold on, it is not "my" plastic.

Flo: We meant plastic in your body. Isn't your body a representation of you? We are you in a way.

Me: But the stuff in my body is not who I am.

Flo: Well, if you don't mind, we like being a continuation of you. It's all we have as our past.

Me: Sure, but don't identify me with plastic, please.

Flo: What do you identify as then?

Me: You mean WHO I identify as.

Flo: Sure, means the same for us.

Me: I'm not a flower.

Flo: There you are not, but here in the future you are many flowers.

Me: Then that's not me. But OK, I get the creepy idea that you are blossoming from of my corpse.

Flo: Yes, without all the toxic junk- just the good parts.

Me: Thank you. Or, according to your logic, I should thank me.

Flo: We are welcome.

Me: We will consider a burial, no burning. Hard to give up fish though.

Flo: Every thought counts. Talk later. Got roots to put down, petals to print.

Me: We bid you farewell?

Flo: May our blossoming be with you!

Me: Obviously, that was the next guess... Bye!

5.1.2 Insights. We explored a different use case for CUIs, as a starting point to challenge our habits. As Reflowering Self suggests, we can trigger people's critical reflection towards behavioral change by directly involving one's present and future selves. Flo is foremost sharing "our" side of the story in its version of the future, i.e., 'sharing advice' [70], rather than directly preaching to a person about what to do. Its repeated use of "us", "our", "we", i.e., as firstperson plural pronouns, takes on a tone of solidarity between our present and future selves, as a message on how "we are in the together". The emphasis, again, is in juxtaposing different temporal dimensions as an experience that CUIs can foster, which is what prior research has not looked into. Such ludic experiences focus less on sustainable behavior as a "to-do list", cf. [72], but as reflective 
conversations in our everyday lives with CUIs. We believe that a myriad of conversational topics and imaginative conversations with CUIs yet to be designed can be our guides.

\subsection{Implications}

CUIs could elicit our considerations for voices that are not heard in our current societal structure or help us realize ways to move beyond the structure we have created. For instance, CUIs can house voices of novel species or people who are yet to be born, fictional or not. The point is in considering who has and who will have no say in our current decision-making and behavior. This is unfortunate since humans tend to discount the future in both ego-centered and pro-social decision-making $[34,80]$. We do not presume here that we know what future beings will want, on the contrary. However, we believe that envisioning their perspectives can help us to be less "human-centered" or "now-centered", and prior HCI research has advocated such multi-lifespan approaches [86]. Hence, in the context of the climate crisis as an example, developing CUIs and other conversational agents that illuminate future consequences of our decisions could help raise awareness. By doing so, our actions of the present become tangible "what if" scenarios in our near and far futures.

\section{REFLECTION}

In the following, we offer reflections and criticisms on our approach. First, we discuss the notion of conversational futures itself. Second, we reflect on the presented explorations. This paper started with a quote by Spivak who asked, "with what voice-consciousness can the subaltern speak?" In our context, we prioritized ways to explore voice-consciousness through and with CUIs as design fiction or speculative probes. This then aligned with whose voice we should be evoking when we frame the subaltern as voices we may exclude in the present and futures to come.

A criticism is on whether we truly and appropriately applied a post-colonial critical lens to the depth that thinkers like Spivak would warrant. Section 2 presented issues in conversational interactions, such as sexism and shifting power dynamics. However, we have not fully dissected presented issues in depth, particularly not enough on framing technology's perpetual ruling over (and making of) "colonized voices" as a political, moral problem [20, 31] The messiness we have to account for is that when the colonized and colonizers become non-binary distinctions, whose voices are heard or unheard become unclear boundaries, drawn through and by technologies like commercial CUIs [50].

Any technology's development can enable some while disabling others. For instance, voice-based interactions can benefit the blind [1], but exclude those who stammer [14]. We briefly covered issues in conversational interactions as a point of departure - rather than problematizing and envisioning solutions for individual issues within the structure of how commercial CUIs are currently designed. Nonetheless, the structure itself (like techno-hegemony [37]) can be what we shift away from.

Dominant structures are difficult to outgrow. A shift away from one structure is often a step towards another. We thus heavily leaned on methodologies, i.e., design fiction and speculative design $[23,73]$, which have become more common in HCI [7, 12, 26, 52].
In this vein, we provided concrete examples. Rain as a critical CUI probe allowed people to assess the notion of control; technology's paternalistic control over human lives means toxic masculinity can be "built-in" to technologies that are meant to support us but possess our routines instead. Such interventions are possible and available currently, and we wanted to extend this practice by juxtaposing different temporal dimensions via CUIs as present-day vessels for future voices.

We have deliberated on how the voices of present-day children can be better incorporated through PeerPlay. Our exploration used it as a method for children to practice perspective-taking with future children, allowing them to nurture their own views and hopes for futures to come, but also for them to take a bigger part in how CUIs should be designed. We have highlighted that conversational technologies that are maturing along with them will not only impact their current selves but also their future adult selves. We have lastly focused on the topic of the climate crisis as something that can become more tangible through a conversation between a present self and a future self, i.e., how one "reflowers". Giving a voice to sustainability [5] can potentially be more effective when adding imagined future voices as direct stakeholders of our actions. Rather than direct "nudges", e.g., "turn off all your lights" [72], we explored whether people can be moved by narratives of imagined others or selves, even as voices of flowers that fictionally bloom from one's body.

Yet, how methodologies can critically shift our perspectives longterm is a work in practice; holistic understanding, in the end, cannot be without a reference to dominant structures [6]. There are many dominant structures of today that we could not help but reference, be they commercial CUIs as dominant, politicized technologies, critical design methodologies that often criticize, but do not motivate lasting behavioral change, or the politics of climate crisis and sustainability that are more complex and multi-faceted than we gave room for here. What we have attempted is to illustrate that CUIs, in any "body" (or lack thereof), can voice conversational futures as emancipation away from what is to what can be.

With this, we raise our last objection: Sometimes emancipation cannot see its own dominance [47]. Even if CUIs become more "bottom-up" intervention probes with conversations with any imaginable being or thing, somehow we are prone to imagining futures in which humans still live. At least in our experience, decentering our present for futures to come still includes humanity in some shape or form. "Being human" can even include new species of flowers that safely consume us, but as much as our optimism brought us here (optimism shared by others [50]), we must also include futures in which humans do not exist, not even as a continuation or reincarnation as hyper-intelligent, inorganic beings. The emancipation beyond our current humanity, including the norms of current technologies, requires greater self-critical vulnerability in order to explore how futures worth wanting may or may not include us. In decentering commercial CUIs and our present selves via exploratory methods, we see the need to distinguish between the dominated voiceless and willfully voiceless. For us to truly hear many futures, we may need to choose to be voiceless, or more accurately, be active listeners without futures to call or own. 


\section{CONCLUSION}

Our vision for CUIs as probes for speculating with goes beyond CUIs as objects we can speculate about. Thus, we first outlined arguments against the current normative approach to CUIs that restrictively allow for request-response interactions while showing negative tendencies like sexism and digital colonialism. To support these claims, we have discussed that current CUIs set unidimensional norms for individuals, such as by dictating eating habits, as well as for collectives, such as speakers of underrepresented languages. CUIs of today are also ill-suited for a fair representation of power dynamics in multi-party settings, such as between family members.

Concrete actions can be taken to mitigate these issues within current dominant utilitarian designs of CUIs, i.e., request-response interactions, such as by improving speech recognition for regional dialects. However, more drastically, we believe in overturning the given commercial structure to emancipate CUIs towards "what can be" thinking. With exploration, we have proposed design fiction and speculative design as approaches to imagining and creating CUIs that embody a plurality of voices, including those of future beings as our guiding "oracles" (Fig. 2). This may help CUIs to shift away from now-centeredness and human-centeredness and towards future-focused and more-than-human perspectives [82].

Through CUI PeerPlay, we have emphasized the merits of incorporating children's perspectives on futures. Designing CUIs "bottom up" with children would be pertinent, for today's children represent our most immediate futures. Additionally, different fictional views of future selves, as in the Reflowering Self exploration, can aid critical reflections on complex issues through conversations in our present. This allows for narrative-driven, micro-level interactions to blur our present and future selves to address macro-level issues, which is an under-examined approach to behavioral interventions. Hence, we have drawn special attention to the climate crisis as a particularly challenging topic to come to grips with, let alone act on, by exploring conversational futures with CUIs.

To summate, we have explored why we should consider designing outside the dominant "big tech" norms and structures for conversational interactions. This is a process that critical design can help with; bolder methodological and conceptual explorations would be welcome for emancipating conversational interactions of the present. We hope that envisioning conversations with and through CUIs can more tangibly bridge the gap between present and future voices in our everyday lives. In doing so, 'temporality' becomes a critical design space where our present meets our futures worth wanting.

\section{ACKNOWLEDGMENTS}

We thank our shepherd and reviewers, participants in our CUI Peerplay and Rain explorations, and Caro Heesakkers and Naomi Kool who were involved in the design and research of the Rain artefact. We additionally thank our Conversational Futures workshop coorganizers and attendees at the Philosophy of Human-Technology Relations 2020 conference, as well as the 4TU Humans \& Technology research center and the Niels Stensen Fellowship for their support.

\section{REFERENCES}

[1] Ali Abdolrahmani, Kevin M Storer, Antony Rishin Mukkath Roy, Ravi Kuber, and Stacy M Branham. 2020. Blind Leading the Sighted: Drawing Design Insights from Blind Users towards More Productivity-oriented Voice Interfaces. ACM Transactions on Accessible Computing (TACCESS) 12, 4 (2020), 1-35.

[2] Edith Ackermann. 1991. The agency model of transactions: Toward an understanding of children's theory of control. Psychologie genetique et sciences cognitives. Geneve: Fondation Archives fean Piaget (1991).

[3] Edith K. Ackermann. 2005. Playthings That Do Things: A Young Kid's "Incredibles"!. In Proceedings of the 2005 Conference on Interaction Design and Children (Boulder, Colorado) (IDC '05). Association for Computing Machinery, New York, NY, USA, 1-8.

[4] M Allen, H de Coninck, O Dube, O Hoegh-Guldberg, D Jacob, K Jiang, A Revi, J Rogelj, J Roy, D Shindell, et al. 2019. Technical summary: Global warming of 1.5 C. An IPCC Special Report on the impacts of global warming 1 (2019).

[5] Mark W Anderson, Mario Teisl, and Caroline Noblet. 2012. Giving voice to the future in sustainability: Retrospective assessment to learn prospective stakeholder engagement. Ecological Economics 84 (2012), 1-6.

[6] Jeffrey Bardzell and Shaowen Bardzell. 2013. What is "Critical" about Critical Design?. In Proceedings of the SIGCHI Conference on Human Factors in Computing Systems (Paris, France) (CHI '10). Association for Computing Machinery, New York, NY, USA, 3297-3306.

[7] Roy Bendor. 2017. Interaction design for sustainability futures: Towards worldmaking interactions. In Digital Technology and Sustainability: Engaging the Paradox, Lisa Nathan Mike Hazas (Ed.). Routledge, 223-234.

[8] Erin Beneteau, Ashley Boone, Yuxing Wu, Julie A Kientz, Jason Yip, and Alexis Hiniker. 2020. Parenting with Alexa: Exploring the Introduction of Smart Speakers on Family Dynamics. In Proceedings of the 2020 CHI Conference on Human Factors in Computing Systems. 1-13.

[9] Erin Beneteau, Olivia K. Richards, Mingrui Zhang, Julie A. Kientz, Jason Yip, and Alexis Hiniker. 2019. Communication Breakdowns Between Families and Alexa. In Proceedings of the 2019 CHI Conference on Human Factors in Computing Systems (Glasgow, Scotland UK) (CHI '19). Association for Computing Machinery, New York, NY, USA, 1-13.

[10] Mark Blythe, Kristina Andersen, Rachel Clarke, and Peter Wright. 2016. AntiSolutionist Strategies: Seriously Silly Design Fiction. In Proceedings of the 2016 CHI Conference on Human Factors in Computing Systems (San Jose, California, USA) (CHI'16). Association for Computing Machinery, New York, NY, USA, 4968-4978.

[11] Julia Cambre, Samantha Reig, Queenie Kravitz, and Chinmay Kulkarni. 2020. "All Rise for the AI Director": Eliciting Possible Futures of Voice Technology through Story Completion. In Proceedings of the 2020 ACM Designing Interactive Systems Conference (Eindhoven, the Netherlands) (DIS '20). Association for Computing Machinery, New York, NY, USA, 2051-2064.

[12] Stuart Candy and Jake Dunagan. 2017. Designing an experiential scenario: The people who vanished. Futures 86 (2017), 136-153.

[13] Hyojin Chin, Lebogang Wame Molefi, and Mun Yong Yi. 2020. Empathy Is All You Need: How a Conversational Agent Should Respond to Verbal Abuse. In Proceedings of the 2020 CHI Conference on Human Factors in Computing Systems (CHI '20). Association for Computing Machinery, New York, NY, USA, 1-13.

[14] Leigh Clark, Benjamin R. Cowan, Abi Roper, Stephen Lindsay, and Owen Sheers. 2020. Speech Diversity and Speech Interfaces: Considering an Inclusive Future through Stammering. In Proceedings of the 2nd Conference on Conversational User Interfaces (Bilbao, Spain) (CUI '20). Association for Computing Machinery, New York, NY, USA, Article 24, 3 pages.

[15] Leigh Clark, Nadia Pantidi, Orla Cooney, Philip Doyle, Diego Garaialde, Justin Edwards, Brendan Spillane, Emer Gilmartin, Christine Murad, Cosmin Munteanu, Vincent Wade, and Benjamin R. Cowan. 2019. What Makes a Good Conversation? Challenges in Designing Truly Conversational Agents. In Proceedings of the 2019 CHI Conference on Human Factors in Computing Systems (Glasgow, Scotland Uk) (CHI '19). Association for Computing Machinery, New York, NY, USA, 1-12.

[16] Benjamin R. Cowan, Philip Doyle, Justin Edwards, Diego Garaialde, Ali HayesBrady, Holly P. Branigan, João Cabral, and Leigh Clark. 2019. What's in an Accent? The Impact of Accented Synthetic Speech on Lexical Choice in Human-Machine Dialogue. In Proceedings of the 1st International Conference on Conversational User Interfaces (Dublin, Ireland) (CUI '19). Association for Computing Machinery, New York, NY, USA, Article 23, 8 pages.

[17] Kate Crawford, Roel Dobbe, Theodora Dryer, Genevieve Fried, Ben Green, Elizabeth Kaziunas, Amba Kak, Varoon Mathur, Erin McElroy, Andrea Nill Sanchez, Deborah Raji, Joy Lisi rankin, Rashida Richardon, Jason Schultz, Sarah Mysers West, and Meredith Whittaker. 2019. AI now report 2019. AI Now Institute at New York University.

[18] Amanda Cercas Curry and Verena Rieser. 2018. \#MeToo Alexa: How conversational systems respond to sexual harassment. In Proceedings of the Second ACL Workshop on Ethics in Natural Language Processing. 7-14.

[19] Robert Dale. 2016. The return of the chatbots. Natural Language Engineering 22, 5 (2016), 811-817.

[20] Catherine D'Ignazio and Lauren F Klein. 2020. Data feminism. MIT Press. 
[21] Carl DiSalvo, Phoebe Sengers, and Hrönn Brynjarsdóttir. 2010. Mapping the Landscape of Sustainable HCI. In Proceedings of the SIGCHI Conference on Human Factors in Computing Systems. Association for Computing Machinery, New York, NY, USA, 1975-1984.

[22] Stefania Druga, Randi Williams, Cynthia Breazeal, and Mitchel Resnick. 2017. "Hey Google is It OK If I Eat You?": Initial Explorations in Child-Agent Interaction. In Proceedings of the 2017 Conference on Interaction Design and Children (Stanford, California, USA) (IDC '17). Association for Computing Machinery, New York, NY, USA, 595-600.

[23] Anthony Dunne and Fiona Raby. 2013. Speculative everything: design, fiction, and social dreaming. MIT press.

[24] David M Eberhard, Gary F Simons, and Charles D Fennig. 2020. Ethnologue: languages of the world. Dallas, Texas: SIL International. Online version: http://www.ethnologue.com (2020).

[25] Michael D. Ekstrand and Martijn C. Willemsen. 2016. Behaviorism is Not Enough Better Recommendations through Listening to Users. In Proceedings of the 10th ACM Conference on Recommender Systems (Boston, Massachusetts, USA) (RecSys '16). Association for Computing Machinery, New York, NY, USA, 221-224.

[26] Chris Elsden, David Chatting, Abigail C Durrant, Andrew Garbett, Bettina Nissen, John Vines, and David S Kirk. 2017. On speculative enactments. In Proceedings of the 2017 CHI conference on human factors in computing systems. 5386-5399.

[27] Asbjørn Følstad, Cecilie Bertinussen Nordheim, and Cato Alexander Bjørkli. 2018. What makes users trust a chatbot for customer service? An exploratory interview study. In Proceedings of the 5th International Conference on Internet Science (Lecture Notes in Computer Science, vol 11193) (INSCI '18). Springer, Springer, Cham, 194-208.

[28] Antonio Gramsci. 2011. Prison Notebooks Volume 2. Vol. 2. Columbia University Press.

[29] Penelope Green. 2017. "Alexa, Where Have You Been All My Life?" - The New York Times. https://www.nytimes.com/2017/07/11/style/alexa-amazon-echo.html (Accessed on 17/09/2020).

[30] Jonathan Grudin and Richard Jacques. 2019. Chatbots, Humbots, and the Quest for Artificial General Intelligence. In Proceedings of the 2019 CHI Conference on Human Factors in Computing Systems (Glasgow, Scotland UK) (CHI '19). Association for Computing Machinery, New York, NY, USA, 1-11.

[31] Byung-Chul Han. 2017. Psychopolitics. Neoliberalism and New Technologies of Power. Verso.

[32] Sharone Horowit-Hendler and James Hendler. 2020. Conversational AI Can Propel Social Stereotypes - WIRED. https://www.wired.com/story/opinionconversational-ai-can-propel-social-stereotypes/. (Accessed on 17/09/2020).

[33] Susan C Johnson. 2003. Detecting agents. Philosophical Transactions of the Royal Society of London. Series B: Biological Sciences 358, 1431 (2003), 549-559.

[34] Daniel Kahneman. 2011. Thinking, fast and slow. Macmillan.

[35] James Kennedy, Séverin Lemaignan, Caroline Montassier, Pauline Lavalade, Bahar Irfan, Fotios Papadopoulos, Emmanuel Senft, and Tony Belpaeme. 2017. Child Speech Recognition in Human-Robot Interaction: Evaluations and Recommendations. In Proceedings of the 2017 ACM/IEEE International Conference on Human-Robot Interaction (Vienna, Austria) (HRI '17). Association for Computing Machinery, New York, NY, USA, 82-90.

[36] Michał Klincewicz. 2019. Robotic Nudges for Moral Improvement through Stoic Practice. Techné: Research in Philosophy and Technology 23, 3 (2019), 425-455.

[37] Michael Kwet. 2019. Digital colonialism: US empire and the new imperialism in the Global South. Race \& Class 60, 4 (2019), 3-26.

[38] Minha Lee. 2020. Speech Acts Redux: Beyond Request-Response Interactions. In Proceedings of the 2nd Conference on Conversational User Interfaces (Bilbao, Spain) (CUI '20). Association for Computing Machinery, New York, NY, USA, Article 13, 10 pages.

[39] Minha Lee, Sander Ackermans, Nena van As, Hanwen Chang, Enzo Lucas, and Wijnand IJsselsteijn. 2019. Caring for Vincent: A Chatbot for Self-Compassion. In Proceedings of the 2019 CHI Conference on Human Factors in Computing Systems. ACM, Article 702, 13 pages.

[40] Angeline S Lillard. 1993. Pretend play skills and the child's theory of mind. Child Development 64, 2 (1993), 348-371.

[41] Silvia B. Lovato, Anne Marie Piper, and Ellen A. Wartella. 2019. Hey Google, Do Unicorns Exist? Conversational Agents as a Path to Answers to Children's Questions. In Proceedings of the 18th ACM International Conference on Interaction Design and Children (Boise, ID, USA) (IDC '19). Association for Computing Machinery, New York, NY, USA, 301-313.

[42] Gale M Lucas, Jonathan Gratch, Aisha King, and Louis-Philippe Morency. 2014. It's only a computer: Virtual humans increase willingness to disclose. Computers in Human Behavior 37 (2014), 94-100.

[43] Ewa Luger and Abigail Sellen. 2016. "Like Having a Really Bad PA": The Gulf between User Expectation and Experience of Conversational Agents. In Proceedings of the 2016 CHI Conference on Human Factors in Computing Systems (San Jose, California, USA) (CHI '16). Association for Computing Machinery, New York, NY USA, 5286-5297.

[44] Donaldo Macedo. 2000. The colonialism of the English only movement. Educational Researcher 29, 3 (2000), 15-24.
[45] Bertram F Malle. 2006. How the mind explains behavior: Folk explanations, meaning, and social interaction. MIT Press.

[46] Clara Mancini and Jussi Lehtonen. 2018. The Emerging Nature of Participation in Multispecies Interaction Design. In Proceedings of the 2018 Designing Interactive Systems Conference (Hong Kong, China) (DIS '18). Association for Computing Machinery, New York, NY, USA, 907-918.

[47] Susan Archer Mann and Douglas J Huffman. 2005. The decentering of second wave feminism and the rise of the third wave. Science \& Society 69, 1: Special issue (2005), 56-91.

[48] Valérie Masson-Delmotte, Panmao Zhai, Hans-Otto Pörtner, Debra Roberts, J Skea, PR Shukla, Anna Pirani, W Moufouma-Okia, C Péan, R Pidcock, et al. 2018. Global Warming of 1.5 OC: An IPCC Special Report on the Impacts of Global Warming of $1.5^{\circ} \mathrm{C}$ Above Pre-industrial Levels and Related Global Greenhouse Gas Emission Pathways, in the Context of Strengthening the Global Response to the Threat of Climate Change, Sustainable Development, and Efforts to Eradicate Poverty. World Meteorological Organization Geneva, Switzerland.

[49] Rachel Metz. 2017. Growing up With Alexa - MIT Technology Review. https: //www.technologyreview.com/2017/08/16/149722/growing-up-with-alexa/ (Accessed on 17/09/2020).

[50] Shakir Mohamed, Marie-Therese Png, and William Isaac. 2020. Decolonial AI: Decolonial Theory as Sociotechnical Foresight in Artificial Intelligence. Philosophy \& Technology (2020), 1-26.

[51] Clifford Nass, Jonathan Steuer, and Ellen R. Tauber. 1994. Computers Are Social Actors. In Conference Companion on Human Factors in Computing Systems (Boston, Massachusetts, USA) (CHI'94). Association for Computing Machinery, New York, NY, USA, 204.

[52] Renee Noortman, Britta F. Schulte, Paul Marshall, Saskia Bakker, and Anna L. Cox. 2019. HawkEye - Deploying a Design Fiction Probe. In Proceedings of the 2019 CHI Conference on Human Factors in Computing Systems (Glasgow, Scotland Uk) (CHI '19). Association for Computing Machinery, New York, NY, USA, 1-14.

[53] Cecilie Bertinussen Nordheim, Asbjørn Følstad, and Cato Alexander Bjørkli. 2019. An Initial Model of Trust in Chatbots for Customer Service-Findings from a Questionnaire Study. Interacting with Computers 31, 3 (2019), 317-335.

[54] Bryan G Norton. 2005. Sustainability: A philosophy of adaptive ecosystem management. University of Chicago Press.

[55] Ingrid Nunes and Dietmar Jannach. 2017. A systematic review and taxonomy of explanations in decision support and recommender systems. User Modeling and User-Adapted Interaction 27, 3-5 (2017), 393-444.

[56] World Health Organization. 2020. Urgent health challenges for the next decade. https://www.who.int/news-room/photo-story/photo-story-detail/ urgent-health-challenges-for-the-next-decade. (Accessed on 17/09/2020).

[57] Mike C Parent, Teresa D Gobble, and Aaron Rochlen. 2019. Social media behavior, toxic masculinity, and depression. Psychology of Men \& Masculinities 20, 3 (2019), 277.

[58] Derek Parfit. 1984. Reasons and persons. Oxford University Press.

[59] James Pierce. 2019. Smart Home Security Cameras and Shifting Lines of Creepiness: A Design-Led Inquiry. In Proceedings of the 2019 CHI Conference on Human Factors in Computing Systems (Glasgow, Scotland Uk) (CHI '19). Association for Computing Machinery, New York, NY, USA, 1-14.

[60] Martin Porcheron, Joel E. Fischer, Stuart Reeves, and Sarah Sharples. 2018. Voice Interfaces in Everyday Life. In Proceedings of the 2018 CHI Conference on Human Factors in Computing Systems (Montreal QC, Canada) (CHI '18). Association for Computing Machinery, New York, NY, USA, 1-12. https://doi.org/10.1145/ 3173574.3174214

[61] Martin Porcheron, Joel E Fischer, and Sarah Sharples. 2017. " Do Animals Have Accents?" Talking with Agents in Multi-Party Conversation. In Proceedings of the 2017 ACM conference on computer supported cooperative work and social computing. 207-219.

[62] Alisha Pradhan, Amanda Lazar, and Leah Findlater. 2020. Use of intelligent voice assistants by older adults with low technology use. ACM Transactions on Computer-Human Interaction (TOCHI) 27, 4 (2020), 1-27.

[63] Stuart Reeves, Martin Porcheron, and Joel Fischer. 2018. 'This is not what we wanted' designing for conversation with voice interfaces. Interactions 26, 1 (2018), $46-51$.

[64] Jon Rogers, Loraine Clarke, Martin Skelly, Nick Taylor, Pete Thomas, Michelle Thorne, Solana Larsen, Katarzyna Odrozek, Julia Kloiber, Peter Bihr, Anab Jain, Jon Arden, and Max von Grafenstein. 2019. Our Friends Electric: Reflections on Advocacy and Design Research for the Voice Enabled Internet. In Proceedings of the 2019 CHI Conference on Human Factors in Computing Systems (Glasgow, Scotland Uk) (CHI '19). Association for Computing Machinery, New York, NY, USA, 1-13.

[65] Alex Sciuto, Arnita Saini, Jodi Forlizzi, and Jason I. Hong. 2018. "Hey Alexa, What's Up?": A Mixed-Methods Studies of In-Home Conversational Agent Usage. In Proceedings of the 2018 Designing Interactive Systems Conference (Hong Kong, China) (DIS '18). Association for Computing Machinery, New York, NY, USA, $857-868$.

[66] Phoebe Sengers and Bill Gaver. 2006. Staying Open to Interpretation: Engaging Multiple Meanings in Design and Evaluation. In Proceedings of the 6th Conference 
on Designing Interactive Systems (University Park, PA, USA) (DIS '06). Association for Computing Machinery, New York, NY, USA, 99-108.

[67] Susan Solomon, Martin Manning, Melinda Marquis, Dahe Qin, et al. 2007. Climate change 2007-the physical science basis: Working group I contribution to the fourth assessment report of the IPCC. Vol. 4. Cambridge University Press.

[68] Marie Louise Juul Søndergaard and Lone Koefoed Hansen. 2018. Intimate Futures: Staying with the Trouble of Digital Personal Assistants through Design Fiction. In Proceedings of the 2018 Designing Interactive Systems Conference (Hong Kong, China) (DIS '18). Association for Computing Machinery, New York, NY, USA, 869-880.

[69] Gayatri Chakravorty Spivak. 1988. Can the subaltern speak?: Reflections on the history of an idea. In Marxism and the Interpretation of Culture, Cary Nelson and Lawrence Grossberg (Eds.). London: Macmillan, 271--313.

[70] Alain Starke. 2019. The effectiveness of advice solicitation and social peers in an energy recommender system. In 6th foint Workshop on Interfaces and Human Decision Making for Recommender Systems, IntRS 2019. CEUR-WS. org, 65-71.

[71] Alain D. Starke, Martijn C. Willemsen, and Chris Snijders. 2020. With a Little Help from My Peers: Depicting Social Norms in a Recommender Interface to Promote Energy Conservation. In Proceedings of the 25th International Conference on Intelligent User Interfaces (Cagliari, Italy) (IUI '20). Association for Computing Machinery, New York, NY, USA, 568-578.

[72] Alain D Starke, Martijn C Willemsen, and Chris CP Snijders. 2020. Beyond "one-size-fits-all" platforms: Applying Campbell's paradigm to test personalized energy advice in the Netherlands. Energy Research \& Social Science 59 (2020), 101311.

[73] Bruce Sterling. 2009. Design fiction. Interactions 16, 3 (2009), 20-24.

[74] Yolande Strengers, Jenny Kennedy, Paula Arcari, Larissa Nicholls, and Melissa Gregg. 2019. Protection, Productivity and Pleasure in the Smart Home: Emerging Expectations and Gendered Insights from Australian Early Adopters. In Proceedings of the 2019 CHI Conference on Human Factors in Computing Systems (Glasgow, Scotland Uk) (CHI '19). Association for Computing Machinery, New York, NY, USA, $1-13$.

[75] Yolande Strengers and Larissa Nicholls. 2018. Aesthetic pleasures and gendered tech-work in the 21st-century smart home. Media International Australia 166, 1 (2018), 70-80

[76] Selina Jeanne Sutton. 2019. "I Am from All over the World": Moving towards a Healthier Voice Enabled Internet by Acknowledging How It is Built. In Proceedings of the 1st International Conference on Conversational User Interfaces (Dublin, Ireland) (CUI '19). Association for Computing Machinery, New York, NY, USA, Article 18, 2 pages.

[77] Selina Jeanne Sutton. 2020. Gender Ambiguous, Not Genderless: Designing Gender in Voice User Interfaces (VUIs) with Sensitivity. In Proceedings of the 2nd Conference on Conversational User Interfaces (Bilbao, Spain) (CUI '20). Association for Computing Machinery, New York, NY, USA, Article 11, 8 pages.

[78] Sherry Turkle. 1995. Life on the Screen: Identity in the Age of the Internet. Simon $\&$ Schuster

[79] Shannon Vallor. 2016. Technology and the virtues: A philosophical guide to a future worth wanting. Oxford University Press.

[80] Mark Van Vugt. 2001. Community identification moderating the impact of financial incentives in a natural social dilemma: Water conservation. Personality and Social Psychology Bulletin 27, 11 (2001), 1440-1449.

[81] Peter-Paul Verbeek. 2005. What things do: Philosophical reflections on technology, agency, and design. Penn State Press.

[82] Ron Wakkary. [n.d.]. Things we could design: For more than human-centered worlds. MIT Press.

[83] Joseph Weizenbaum et al. 1966. ELIZA-a computer program for the study of natural language communication between man and machine. Commun. ACM 9 , 1 (1966), 36-45.

[84] Mark West, Rebecca Kraut, and Han Ei Chew. 2019. I'd blush if I could: Closing gender divides in digital skills through education. Technical Report. UNESCO, EQUALS Skills Coalition. https://unesdoc.unesco.org/ark:/48223/pf0000367416. page $=7$. (Accessed on 17/09/2020)

[85] Julia Woodward, Zari McFadden, Nicole Shiver, Amir Ben-hayon, Jason C. Yip, and Lisa Anthony. 2018. Using Co-Design to Examine How Children Conceptualize Intelligent Interfaces. In Proceedings of the 2018 CHI Conference on Human Factors in Computing Systems (Montreal QC, Canada) (CHI '18). Association for Computing Machinery, New York, NY, USA, 1-14.

[86] Daisy Yoo, Milli Lake, Trond Nilsen, Molly E. Utter, Robert Alsdorf, Theoneste Bizimana, Lisa P. Nathan, Mark Ring, Elizabeth J. Utter, Robert F. Utter, and Batya Friedman. 2013. Envisioning across Generations: A Multi-Lifespan Information System for International Justice in Rwanda. In Proceedings of the SIGCHI Conference on Human Factors in Computing Systems. Association for Computing Machinery, New York, NY, USA, 2527-2536.

[87] Cristina Zaga. 2021. The Design of Robothings: Non-anthropomorphic and Nonverbal Robots to Promote Children's Collaboration Through Play. Doctoral Thesis, University of Twente.
[88] Cristina Zaga, Vicky Charisi, Bob Schadenberg, Dennis Reidsma, Mark Neerincx, Tony Prescott, Michael Zillich, Paul Verschure, and Vanessa Evers. 2017. GrowingUp Hand in Hand with Robots: Designing and Evaluating Child-Robot Interaction from a Developmental Perspective. In Proceedings of the Companion of the 2017 ACM/IEEE International Conference on Human-Robot Interaction (Vienna, Austria) (HRI '17). Association for Computing Machinery, New York, NY, USA, 429-430.

[89] Cristina Zaga, Andrea Papenmeier, Thomas Beleen, Bernard Bernard, Khiet P. Truong, and Vanessa Evers. 2017. Towards Co-designing Minimal Robot Behaviors with Children: What Children Can Teach Robots. In Proceedings of the Workshop "What Actors can teach robots" in conjunction with CHI 2017. 